\title{
Is the bench getting closer to the bedside in the war on cancer? A quick look at prostate cancer
}

\author{
Robert Kypta ${ }^{1,2}$, Miguel Unda $^{3}$ and Arkaitz Carracedo ${ }^{1,4 *}$ \\ ' CIC bioGUNE, Technology Park of Bizkaia, Derio, Spain \\ 2 Department of Surgery and Cancer, Imperial College London, London, UK \\ 3 Hospital de Basurto, Bilbao, Spain \\ 4 IKERBASQUE Basque Foundation for Science, Bilbao, Spain \\ *Correspondence: acarracedo@cicbiogune.es
}

From the beginnings of the War on Cancer, officially inaugurated in the early seventies by Richard Nixon, research priorities to identify and attack the main weaknesses of tumor cells have evolved, following the rhythm of technology. From the use of overtly toxic and undiscriminating drugs to the detailed annotation of cancers on a patient-to-patient basis through the use of "Omics" approaches, research has struggled in the search for a cure. Is current basic research having a more immediate impact on nurturing clinical work? Here we discuss the recent contributions of basic research to prostate cancer therapy, and the factors contributing to a change in the way we fight this disease, with a focus on hormone signaling and metabolism.

Prostate cancer is the fifth cause of death by cancer worldwide (data retrieved from the WHO), second in the male population. Prostate cancer arises from the aberrant proliferation of epithelial cells, termed prostate intraepithelial neoplasia (PIN). Cancer cells can further alter the structure of the gland, leading to the disruption of the basal cell layer and loss of basement membrane integrity and the onset of invasive prostate cancer lesions. Upon sustained hormone-ablation therapy, invasive prostate cancer frequently acquires castration-resistant features and gains metastatic potential, which accounts for a large fraction of morbidity (Moul and Dawson, 2012). Much of the effort dedicated to prostate cancer research has been oriented at developing efficient therapies for the most deadly form of the disease, castration-resistant prostate cancer (CRPC), which often exhibits aberrant production of androgens or activating mutations in the Androgen Receptor (AR) gene, together with inactivating mutations in genes such as the tumor suppressor PTEN (Friedlander et al., 2012). Recent studies indicate that inhibi- tors of androgen synthesis (CYP17) and AR signaling exhibit antitumoral activity in CRPC patients. Thus, compounds targeting the androgen pathway have emerged as leading anticancer agents. CYP17 exhibits both 17,20 lyase and 17-hydrolase activity. Whereas the 17,20 lyase activity of CYP17 is involved in androgen synthesis, the 17-hydrolase activity is relevant for glucocorticoid synthesis. Therefore, inhibition of both CYP17 activities results in the reduction of both androgen and glucocorticoid synthesis, which has led to the need of combining CYP17 inhibitors ith glucocorticoid supplementation, in order to avoid undesirable side effects (Attard et al., 2012). The US FDA recently approved the CYP17 inhibitor abiraterone acetate (Zytiga) for the treatment of CRPC (De Bono et al., 2011). In addition, there are inhibitors targeting the 17,20 lyase activity of CYP17 (rather than the 17-hydrolase activity, hence eliminating the need for glucocorticoid supplementation), such as TAK700, in Phase III clinical trials ${ }^{1}$ (refs. NCT01193244 and NCT01193257) and galeterone, a dual CYP17/AR inhibitor in Phase I (see text footnote 1 ref. NCT00959959), that could be adopted as first line therapies for CRPC in the near future.

To date, targeting androgen signaling in CRPC appears to be one of the most attractive approaches, due to the fact that resistance to castration is often associated to extra-gonadal androgen synthesis (adrenal glands, intracrine de novo synthesis) that can be targeted with these new pharmacological inhibitors (Attard et al., 2012). However, these exciting new drugs might still fail to function upon the emergence of resistant cancer cells (Mostaghel et al., 2011). Therefore, and in line with the notion that single anticancer therapy will only be

${ }^{1}$ clinicaltrials.gov an efficient anticancer approach in a handful of cancers with a clear oncogene addiction (Weinstein, 2008; Weinstein and Joe, 2008), the question arises: what will be the best drug combination to cure prostate cancer? Genetically engineered mouse models provide us with a fantastic opportunity to study and understand the biological alterations that occur in the disease, and in turn might facilitate predicting the best pharmacological combination on the basis of the genetic make-up of the cancer.

The tumor suppressor PTEN is among the most mutated/inactivated genes in prostate cancer, with up to $70 \%$ of tumors harboring partial or complete loss of PTEN at presentation (Salmena et al., 2008). While PTEN frequently undergoes loss of heterozygosity, it is mostly in advanced cancers that complete loss is observed. On this basis, a genetic mouse model driven by prostate epithelium-specific loss of Pten was anticipated to be a faithful model for this disease. Indeed, Pten heterozygous mice present PIN lesions in the prostate with long latency (Di Cristofano et al., 1998; Trotman et al., 2003), whereas complete loss of PTEN in the prostate epithelium results in full-penetrance PIN in early stages, and invasive cancer later on, once the underlying senescence response has been evaded (Chen et al., 2005; Alimonti et al., 2010). This mouse model therefore offers two flavors of prostate cancer, onset and progression, which is extremely useful both for biological understanding and therapeutic initiatives. Indeed, this model has led to the characterization of the intimate association between the PI3K pathway and androgen signaling in prostate cancer, with reciprocal feedback loops triggering compensatory activation of these pathways when pharmacological inhibitors are employed (Carver et al., 2011; Mulholland et al., 2011). The idea that emanates from these studies is 
that the best response in patients might be achieved by combined inhibition of PI3K and AR signaling.

The use of mouse models, has also led to a better understanding of the biological contribution of genetic alterations to prostate cancer pathogenesis. In this context, it is worth mentioning the case of a genetic alteration that has provided a new view of the contribution of androgen signaling to prostate cancer, and also changed the dogma about chromosomal rearrangements in solid tumors. It was originally thought that chromosomal translocations, while frequently observed in hematological malignancies and sarcomas, were extremely rare in solid tumors. However, Chinnaiyan's group described that a single translocation could be observed in up to $50 \%$ of prostate cancers. This translocation involved the androgen-regulated promoter of transmembrane protease, serine 2 (TMPRSS2) and an ETS-related protein (ERG). This observation may be key to understanding how androgenic signals rewire cell signaling and the transcriptional landscape. Importantly, mouse modeling was arguably key to a better understanding of the contribution of this genetic alteration to the disease. Transgenic mice in which ERG is placed under the control of androgens (such as TMPRS22 or Probasin promoter) develop invasive cancer, but only in the context of PI3-kinase pathway activation (Carver et al., 2009b; King et al., 2009). The study of these mice indicated that while ERG over-expression was not sufficient to initiate prostate cancer (Carver et al., 2009a), it would result in an invasive phenotype when one allele of PTEN was missing.

In addition to PTEN and ERG, c-Myc is found mutated or over-expressed in a large fraction of prostate cancers (Jenkins et al., 1997; Qian et al., 1997). In line with this notion, mice over-expressing c-Myc develop PIN followed by progression to invasive cancer, and exhibit genetic and histological features reminiscent of human prostate cancer (Ellwood-Yen et al., 2003). Moreover, these two key oncogenic pathways (PTEN-PI3K$\mathrm{AKT}$ and c-Myc) cooperate in the development and progression of prostate cancer. The group of Sawyers recently showed that crossing Pb-Myr-AKT1 and Pb-Myc transgenic mice led to a dramatic acceleration of invasive prostate adenocarcinoma onset with inflammatory features and a reduced dependence on mTOR signaling (Clegg et al., 2011). These data further enforce the notion that targeting Myc in cancer would be of high therapeutic interest, and further studies will determine whether targeting Myc signaling (since Myc protein is largely undruggable) could have a therapeutic benefit in this type of cancer.

During the last couple of years, several independent groups have found evidence for a connection between the reprogramming of cellular metabolism and androgen signaling. This is particularly interesting, as metabolic reprogramming appears to take place in all cancer cells, and so represents an attractive target for therapy (Vander Heiden et al., 2009). On the one hand, androgen signaling promotes a $\mathrm{Ca}^{2+} /$ Calmodulindependent protein kinase kinase beta $(\mathrm{CaMKK} \beta)$-orchestrated metabolic switch, with increased anabolism and the Warburg effect, characterized by increased glucose uptake and lactate production (Massie et al., 2011). On the other hand, metabolomic analysis of androgen-dependent and -independent PCa cell lines has unraveled core differences in cellular metabolism related to androgen signaling (Putluri et al., 2011). In addition, metabolomic studies have allowed not only a better understanding of biological processes, but also potential biomarkers for the progression of the disease (Sreekumar et al., 2009), although we are clearly only at the beginning of an obscure and complex path (Colleselli et al., 2010; Hewavitharana, 2010; Jentzmik et al., 2010, 2011).

Omics, when used wisely, are a definitive source of information for the identification of biomarkers and the definition of molecular subtypes in cancer. This has been beautifully exemplified in breast cancer, where transcriptional gene expression profiles have led to the definition of clinically and therapeutically relevant molecular subtypes (Perou et al., 2000; Wang et al., 2004; Matros et al., 2005; Desmedt et al., 2008), or to the definition of signatures of good and poor prognosis (Van 't Veer et al., 2002). A similar effort has been made for prostate cancer, although a clearly defined portrait of molecular subtypes has not yet emerged. A recent study (Markert et al., 2011) classified tumors on the basis of mRNA microarray signature profiles for stemness, inactivation of tumor suppressors, and activation of oncogenic pathways. This led to the identification of five tumor subsets, one with very poor survival outcome (manifesting signatures for stemness and p53 and PTEN inactivation), one intermediate (characterized by the TMPRSS2-ERG fusion) and three benign. Since this classification was found to be independent of Gleason score, it may help to predict poor outcome in patients.

With all the new technology available and the knowledge we have acquired in the last decade, it becomes clear that evaluating the metabolic alterations occurring at different stages of prostate cancer could offer new biomarkers as well as targets for therapy, which, in combination with the aforementioned approaches, could become a game changer in the diagnosis and treatment of this disease. The relationship between obesity and cancer is, at least in part, largely dependent the effects of obesity on metabolic tissues such as alterations in hormone/cytokine homeostasis (Khandekar et al., 2011). On the one hand, excessive lipid accumulation in the adipose tissue modifies its function, resulting in the secretion of pro-inflammatory cytokines (i.e., TNF-alpha and IL-6), the production of leptin (which has been closely associated to prostate cancer incidence) and reduced levels of adiponectin, which has anticancer properties, among other things. On the other hand, obesity and metabolic disorders can alter the function of the inflammatory system and the production of other hormones, which could have a critical effect on neoplastic cells, such as IGF-1. The metabolic component of prostate cancer leads us to another question: Is the association between prostate cancer occurrence and metabolic diseases, such as obesity, a reflection of more than just a non-cell autonomous, systemic alteration of cancer-promoting factors? Prostate cancer is among the types of tumor that are directly correlated with obesity (Wolin et al., 2010). Moreover, a healthy diet and moderate physical activity in prostate cancer patients subjected to prostatectomy is associated with increased survival (Davies et al., 2011). This concept is particularly important given that prostate cancer is more frequent in men of advanced age, who have a higher incidence of obesity. A local study that included this type of analysis $^{2}$ (Vital study 2005; $N=4220$ ) showed

${ }^{2}$ www2.cajavital.es/salud 
an obesity incidence of nearly $20 \%$ of men $>60$ years old $(6 \%$ higher than in the overall population, 2.6 times more than in the population of 18-40 year-olds). These data suggest that $\mathrm{BMI}$ and the incidence of obesity tend to be higher in the elderly population. An independent study carried out at Basurto Hospital (Bilbao) in 2010 among prostate cancer patients revealed that a high percentage of men (28\%) diagnosed with prostate cancer presented with a BMI $>30$ (average age 68; average BMI $=28.04$; $N=140$ ), classified as obesity. These data in turn suggest that the population suffering from prostate cancer might exhibit a different (higher) incidence of obesity compared to other types of cancer that are detected across a wider range of age. In addition, it calls for a careful evaluation of the particular features and characteristics of prostate cancer in obese patients, as they may represent a clinical sub-group with a differential response to therapy.

In conclusion, the pathogenesis of prostate cancer involves an array of genetic and environmental factors, with an intimate relationship between signaling cascades, metabolic pathways, and hormone signaling. The current mouse models of prostate cancer have proven to be extremely useful to define both the biological basis of the disease and to predict therapeutic efficacy. However, more detailed studies are needed in order to define potential prostate cancer subpopulations, and this should be possible through the integration of new biomarkers, studies of the nutritional habits of patients, and the prevalent mutations.

\section{ACKNOWLEDGMENTS}

Robert Kypta was supported by the Spanish Ministry of Education and Science (SAF2011-30494), The Garfield Weston Foundation, and the Department of Industry, Tourism and Trade (Etortek), and the Department of Innovation Technology of the Government of the Autonomous Community of the Basque Country. Arkaitz Carracedo was supported by the Ramón y Cajal program (Spanish Ministry of Education), by the Marie Curie Reintegration grant (277043), the Basque Government of education (PI2012-03), and by ISCIII (PI10/01484). We apologize to those whose publications related to the discussed issues could not be cited owing to space limitations.

\section{REFERENCES}

Alimonti, A., Nardella, C., Chen, Z., Clohessy, J. G., Carracedo, A., Trotman, L. C., Cheng, K., Varmeh, S., Kozma, S. C., Thomas, G., Rosivatz, E., Woscholski, R. Cognetti, F., Scher, H. I., and Pandolfi, P. P. (2010). A novel type of cellular senescence that can be enhanced in mouse models and human tumor xenografts to suppress prostate tumorigenesis. J. Clin. Invest. 120, 681-693.

Attard, G., Reid, A. H., Auchus, R. J., Hughes, B. A., Cassidy, A. M., Thompson, E., Oommen, N. B. Folkerd, E., Dowsett, M., Arlt, W., and De Bono, J. S. (2012). Clinical and biochemical consequences of CYP17A1 inhibition with abiraterone given with and without exogenous glucocorticoids in castrate men with advanced prostate cancer. J. Clin. Endocrinol. Metab. 97, 507-516.

Carver, B. S., Chapinski, C., Wongvipat, J., Hieronymus, H., Chen, Y., Chandarlapaty, S., Arora, V. K., Le, C. Koutcher, J., Scher, H., Scardino, P. T., Rosen, N., and Sawyers, C. L. (2011). Reciprocal feedback regulation of PI3K and androgen receptor signaling in PTENdeficient prostate cancer. Cancer Cell 19, 575-586.

Carver, B. S., Tran, J., Chen, Z., Carracedo-Perez, A., Alimonti, A., Nardella, C., Gopalan, A., Scardino, P. T., Cordon-Cardo, C., Gerald, W., and Pandolfi, P. P. (2009a). ETS rearrangements and prostate cancer initiation. Nature 457, E1; discussion E2-E3.

Carver, B. S., Tran, J., Gopalan, A., Chen, Z., Shaikh, S., Carracedo, A., Alimonti, A., Nardella, C., Varmeh, S., Scardino, P. T., Cordon-Cardo, C., Gerald, W., and Pandolfi, P. P. (2009b). Aberrant ERG expression cooperates with loss of PTEN to promote cancer progression in the prostate. Nat. Genet. 41, 619-624.

Chen, Z., Trotman, L. C., Shaffer, D., Lin, H. K., Dotan, Z. A., Niki, M., Koutcher, J. A., Scher, H. I., Ludwig, T., Gerald, W., Cordon-Cardo, C., and Pandolfi, P. P. (2005). Crucial role of p53-dependent cellular senescence in suppression of Pten-deficient tumorigenesis. Nature 436, 725-730.

Clegg, N. J., Couto, S. S., Wongvipat, J., Hieronymus, H., Carver, B. S., Taylor, B. S., Ellwood-Yen, K., Gerald, W. L., Sander, C., and Sawyers, C. L. (2011). MYC cooperates with $\mathrm{AKT}$ in prostate tumorigenesis and alters sensitivity to mTOR inhibitors. PLoS ONE 6, e17449. doi: 10.1371/journal.pone.0017449

Colleselli, D., Stenzl, A., and Schwentner, C. (2010). Re: florian jentzmik, carsten stephan, kurt miller, et al. Sarcosine in urine after digital rectal examination fails as a marker in prostate cancer detection and identification of aggressive tumours. Eur. Urol. 58, 12-18; Eur. Urol. 58, e51.

Davies, N. J., Batehup, L., and Thomas, R. (2011). The role of diet and physical activity in breast, colorectal, and prostate cancer survivorship: a review of the literature. Br. J. Cancer 105(Suppl. 1), S52-S73.

De Bono, J. S., Logothetis, C. J., Molina, A., Fizazi, K., North, S., Chu, L., Chi, K. N., Jones, R. J., Goodman, O. B. Jr., Saad, F., Staffurth, J. N., Mainwaring, P., Harland, S., Flaig, T. W., Hutson, T. E., Cheng, T., Patterson, H., Hainsworth, J. D., Ryan, C. J., Sternberg, C. N., Ellard, S. L., Flechon, A., Saleh, M., Scholz, M., Efstathiou, E., Zivi, A., Bianchini, D., Loriot, Y., Chieffo, N., Kheoh, T., Haqq, C. M., and Scher, H. I. (2011). Abiraterone and increased survival in metastatic prostate cancer. N. Engl. J. Med. 364, 1995-2005.

Desmedt, C., Haibe-Kains, B., Wirapati, P., Buyse, M., Larsimont, D., Bontempi, G., Delorenzi, M., Piccart, M., and Sotiriou, C. (2008). Biological processes associated with breast cancer clinical outcome depend on the molecular subtypes. Clin. Cancer Res. 14, 5158-5165.

Di Cristofano, A., Pesce, B., Cordon-Cardo, C., and Pandolfi, P. P. (1998). Pten is essential for embryonic development and tumour suppression. Nat. Genet. 19, 348-355.

Ellwood-Yen, K., Graeber, T. G., Wongvipat, J., IruelaArispe, M. L., Zhang, J., Matusik, R., Thomas, G. V. and Sawyers, C. L. (2003). Myc-driven murine prostate cancer shares molecular features with human prostate tumors. Cancer Cell 4, 223-238.

Friedlander, T. W., Roy, R., Tomlins, S. A., Ngo, V. T., Kobayashi, Y., Azameera, A., Rubin, M. A., Pienta, K. J., Chinnaiyan, A., Ittmann, M. M., Ryan, C. J., and Paris, P.L. (2012). Common structural and epigenetic changes in the genome of castration-resistant prostate cancer. Cancer Res. 72, 616-625.

Hewavitharana, A. K. (2010). Re: Florian Jentzmik, Carsten Stephan, Kurt Miller, et al. Sarcosine in urine after digital rectal examination fails as a marker in prostate cancer detection and identification of aggressive tumours. Eur. Urol. 58, 12-18; Eur. Urol. 58, e39-e40; author reply e41-e32.

Jenkins, R. B., Qian, J., Lieber, M. M., and Bostwick, D. G. (1997). Detection of c-myc oncogene amplification and chromosomal anomalies in metastatic prostatic carcinoma by fluorescence in situ hybridization. Cancer Res. 57, 524-531.

Jentzmik, F., Stephan, C., Lein, M., Miller, K., Kamlage, B., Bethan, B., Kristiansen, G., and Jung, K. (2011). Sarcosine in prostate cancer tissue is not a differential metabolite for prostate cancer aggressiveness and biochemical progression. J. Urol. 185, 706-711.

Jentzmik, F., Stephan, C., Miller, K., Schrader, M., Erbersdobler, A., Kristiansen, G., Lein, M., and Jung, K. (2010). Sarcosine in urine after digital rectal examination fails as a marker in prostate cancer detection and identification of aggressive tumours. Eur. Urol. 58, 12-18; discussion 20-11.

Khandekar, M. J., Cohen, P., and Spiegelman, B. M. (2011). Molecular mechanisms of cancer development in obesity. Nat. Rev. Cancer 11, 886-895.

King, J. C., Xu, J., Wongvipat, J., Hieronymus, H., Carver, B. S., Leung, D. H., Taylor, B. S., Sander, C., Cardiff, R. D., Couto, S. S., Gerald, W. L., and Sawyers, C. L. (2009). Cooperativity of TMPRSS2-ERG with PI3kinase pathway activation in prostate oncogenesis. Nat. Genet. 41, 524-526.

Markert, E. K., Mizuno, H., Vazquez, A., and Levine, A J. (2011). Molecular classification of prostate cancer using curated expression signatures. Proc. Natl. Acad. Sci. U.S.A. 108, 21276-21281.

Massie, C. E., Lynch, A., Ramos-Montoya, A., Boren, J., Stark, R., Fazli, L., Warren, A., Scott, H., Madhu, B., Sharma, N., Bon, H., Zecchini, V., Smith, D. M. Denicola, G. M., Mathews, N., Osborne, M., Hadfield, J., Macarthur, S., Adryan, B., Lyons, S. K., Brindle, K. M., Griffiths, J., Gleave, M. E., Rennie, P. S., Neal, D. E., and Mills, I. G. (2011). The androgen receptor fuels prostate cancer by regulating central metabolism and biosynthesis. EMBO J. 30, 2719-2733.

Matros, E., Wang, Z. C., Lodeiro, G., Miron, A., Iglehart, J. D., and Richardson, A. L. (2005). BRCAl promoter methylation in sporadic breast tumors: relationship to gene expression profiles. Breast Cancer Res. Treat. 91, 179-186.

Mostaghel, E. A., Marck, B. T., Plymate, S. R., Vessella, R. L., Balk, S., Matsumoto, A. M., Nelson, P. S., and 
Montgomery, R. B. (2011). Resistance to CYP17A1 inhibition with abiraterone in castration-resistant prostate cancer: induction of steroidogenesis and androgen receptor splice variants. Clin. Cancer Res. $17,5913-5925$.

Moul, J. W., and Dawson, N. (2012). Quality of life associated with treatment of castration-resistant prostate cancer: a review of the literature. Cancer Invest. 30, 1-12.

Mulholland, D. J., Tran, L. M., Li, Y., Cai, H., Morim, A., Wang, S., Plaisier, S., Garraway, I. P., Huang, J., Graeber, T. G., and Wu, H. (2011). Cell autonomous role of PTEN in regulating castration-resistant prostate cancer growth. Cancer Cell 19, 792-804.

Perou, C. M., Sorlie, T., Eisen, M. B., Van De Rijn, M., Jeffrey, S. S., Rees, C. A., Pollack, J. R., Ross, D. T., Johnsen, H., Akslen, L. A., Fluge, O., Pergamenschikov, A., Williams, C., Zhu, S. X., Lonning, P. E., BorresenDale, A. L., Brown, P. O., and Botstein, D. (2000). Molecular portraits of human breast tumours. Nature 406, 747-752.

Putluri, N., Shojaie, A., Vasu, V. T., Nalluri, S., Vareed, S. K., Putluri, V., Vivekanandan-Giri, A., Byun, J., Pennathur, S., Sana, T. R., Fischer, S. M., Palapattu, G. S., Creighton, C. J., Michailidis, G., and Sreekumar, A. (2011). Metabolomic profiling reveals a role for androgen in activating amino acid metabolism and methylation in prostate cancer cells. PLoS ONE 6, e21417. doi: 10.1371/journal.pone.0021417

Qian, J., Jenkins, R. B., and Bostwick, D. G. (1997). Detection of chromosomal anomalies and c-myc gene amplification in the cribriform pattern of prostatic intraepithelial neoplasia and carcinoma by fluorescence in situ hybridization. Mod. Pathol. 10, 1113-1119.

Salmena, L., Carracedo, A., and Pandolfi, P. P. (2008). Tenets of PTEN tumor suppression. Cell 133, 403-414

Sreekumar, A., Poisson, L. M., Rajendiran, T. M., Khan, A P., Cao, Q., Yu, J., Laxman, B., Mehra, R., Lonigro, R. J., Li, Y., Nyati, M. K., Ahsan, A., Kalyana-Sundaram, S., Han, B., Cao, X., Byun, J., Omenn, G. S., Ghosh, D., Pennathur, S., Alexander, D. C., Berger, A. Shuster, J. R., Wei, J. T., Varambally, S., Beecher, C., and Chinnaiyan, A. M. (2009). Metabolomic profiles delineate potential role for sarcosine in prostate cancer progression. Nature 457, 910-914.

Trotman, L. C., Niki, M., Dotan, Z. A., Koutcher, J. A., Di Cristofano, A., Xiao, A., Khoo, A. S., Roy-Burman, P., Greenberg, N. M., Van Dyke, T., Cordon-Cardo, C., and Pandolfi, P. P. (2003). Pten dose dictates cancer progression in the prostate. PLoS Biol. 1, E59. doi: 10.1371/journal.pbio.0000059

Van't Veer, L. J., Dai, H., Van De Vijver, M. J., He, Y. D., Hart, A.A., Mao, M., Peterse, H.L., Van Der Kooy, K., Marton, M. J., Witteveen, A. T., Schreiber, G. J., Kerkhoven, R. M., Roberts, C., Linsley, P. S., Bernards, R., and Friend, S.H. (2002). Gene expression profiling predicts clinical outcome of breast cancer. Nature 415, 530-536.

Vander Heiden, M. G., Cantley, L. C., and Thompson, C. B. (2009). Understanding the Warburg effect: the metabolic requirements of cell proliferation. Science 324, 1029-1033.
Wang, Z. C., Lin, M., Wei, L. J., Li, C., Miron, A., Lodeiro, G., Harris, L., Ramaswamy, S., Tanenbaum, D. M., Meyerson, M., Iglehart, J. D., and Richardson, A. (2004). Loss of heterozygosity and its correlation with expression profiles in subclasses of invasive breast cancers. Cancer Res. 64, 64-71.

Weinstein, B. (2008). Relevance of the concept of oncogene addiction to hormonal carcinogenesis and molecular targeting in cancer prevention and therapy. Adv. Exp. Med. Biol. 617, 3-13.

Weinstein, I. B., and Joe, A. (2008). Oncogene addiction. Cancer Res. 68, 3077-3080; discussion 3080.

Wolin, K.Y., Carson, K., and Colditz, G. A. (2010). Obesity and cancer. Oncologist 15, 556-565.

Received: 07 February 2012; accepted: 22 March 2012; published online: 12 April 2012.

Citation: Kypta R, Unda M and Carracedo A (2012) Is the bench getting closer to the bedside in the war on cancer? A quick look at prostate cancer. Front. Endocrin. 3:53. doi: 10.3389/fendo.2012.00053

This article was submitted to Frontiers in Cancer Endocrinology, a specialty of Frontiers in Endocrinology. Copyright (c) 2012 Kypta, Unda and Carracedo. This is an open-access article distributed under the terms of the Creative Commons Attribution Non Commercial License, which permits non-commercial use, distribution, and reproduction in other forums, provided the original authors and source are credited. 